\title{
Emotional, neuropsychological, and organic factors: their use in the prediction of persisting postconcussion symptoms after moderate and mild head injuries
}

\author{
Nigel S King
}

\begin{abstract}
Background-After mild and moderate head injuries a range of postconcussion symptoms (PCS) are often reported by patients. Both organic and psychogenic factors can contribute to these. Full recovery from PCS usually occurs within three months of the injury. A significant minority, however, continue to experience symptoms beyond this time. To date, no means of identifying these patients early after injury has been reported. This study investigates whether a combination of neuropsychological, emotional, and traditional measures of severity of head injury taken early after the injury can help predict severity of PCS three months after injury.
\end{abstract}

Methods-50 patients with mild or moderate head injury had a range of measures administered at 7-10 days after injury. These included three tests of divided attention, a PCS rating scale-the Rivermead postconcussion symptoms questionnaire (RPQ), the hospital anxiety and depression scale (HADS), the impact of event scale (IES), and post-traumatic amnesia. An RPQ was then completed by all patients three months after injury.

Results-Stepwise multiple regression analysis was performed with the RPQ score at three months as the dependent measure. A combination of eight of the scores from the early measures gave a multiple correlation coefficient of $\mathbf{R}=$ 0.86 accounting for $74 \%$ of the variance in RPQ scores. The most predictive individual measures were the HADS and IES. Regression analysis with RPQ score at 7-10 days as dependent measure showed that 10 of the scores gave a coefficient of $R=0.84$ accounting for $71 \%$ of the variance.

Conclusions-A combination of measures may significantly aid the prediction of persistent PCS. Five measures: HADS, post-traumatic amnesia, SOMC, PASAT, and $R P Q$ are recommended for their predictive value and clinical utility. Independent cross validation studies are required before these results can be generally applied. They do, however, provide valuable indications regarding those measures that are most likely to demonstrate utility.
$(7$ Neurol Neurosurg Psychiatry 1996;61:75-81)

Keywords: postconcussion symptoms; predictors of mild head injury; head injury

Uncomplicated head injuries resulting in posttraumatic amnesia of less than 24 hours are usually described as being of mild or moderate severity. ${ }^{12}$ A range of postconcussion symptoms (PCS) are often reported after such injuries. These include headaches, dizziness, fatigue, irritability, reduced concentration, sleep disturbance, memory dysfunction, anxiety, sensitivity to noise, double or blurred vision, sensitivity to light, and depression. ${ }^{3-7}$ These symptoms certainly exist ${ }^{8-11}$ although there is still debate as to whether they are best thought of as a syndrome. ${ }^{35}$

Patients with mild or moderate head injuries usually report the resolution of most of their symptoms within three months of their injury. ${ }^{511-13}$ Prospective studies, however, indicate that a significant number still report symptoms at three months after injury and a few at 12 months..$^{514}$ Being able to predict those patients likely to experience persisting symptoms is important as PCS can significantly impair return to work and psychosocial functioning. ${ }^{315}$

No neuropsychological or phenomenological measure has consistently shown a capacity to make this prediction soon after injury-that is, within the first four weeks. Traditional measures of severity of head injury such as duration of post-traumatic amnesia have significant limitations in moderate and mild head injuries $^{16}$ and have been inconclusive when used as predictors of patients with persistent PCS. For example, Middelboe et $a^{14}$ found no significant relation between post-traumatic amnesia and PCS, Jakobsen et al ${ }^{17}$ showed an inverse relation, and Minderhoud et $a l^{18}$ reported direct positive correlations. Neuropsychologial measures such as paragraph recall tests have similarly shown little correlation with PCS $^{19}$ and reaction time tasks have shown both no relation ${ }^{20}$ and positive correlation. ${ }^{17}$ More consistent findings have come from measures of divided attention. The paced auditory serial addition test (PASAT) ${ }^{21}$ and Stroop test ${ }^{22}$ have both been shown to directly mirror the level of PCS reported during the recovery period. ${ }^{23-25}$ Neither of these tests, however, was able to predict early on those 
patients likely to experience persisting symptoms three months after injury.

One factor in the variable nature of these results is likely to be their use of relatively unstandardised measures of the severity of PCS. Most studies have relied on the reported presence or absence of symptoms from a checklist $^{581026}$ or on self reports of the absolute or relative increase in symptoms after trauma. ${ }^{4527}$ Others have used unvalidated numerical rating scales. ${ }^{1121}$ However, a recently developed questionnaire, the Rivermead postconcussion symptom questionnaire (RPQ) (appendix 1) has been shown to measure reliably the severity of PCS (both test-retest and interrater reliability were demonstrated). ${ }^{28}$ The RPQ also generates a very reliable total symptom score, which potentially provides a single numerical gauge of severity of PCS. A second factor in the inconsistent results regarding the prediction of persistent PCS is that emotional and psychogenic problems seem to play a significant part in postconcussion sequelae. Posttraumatic stress $^{14}$ and pre-existing emotional problems ${ }^{4}$ have both been shown to correlate positively with persistent PCS. Indeed, some argue that postconcussion sequelae generally start off on an organic basis but that psychogenic factors are pertinent when the PCS persist. ${ }^{18}$ Such variables need, therefore, to be taken into consideration when attempting to identify patients likely to experience ongoing PCS.

This report investigates whether a combination of neuropsychological, emotional, and traditional measures of severity of head injury taken 7-10 days after trauma can predict those likely to have persistent PCS three months later. The $R P Q$, the hospital anxiety and depression scale (HADS), ${ }^{29}$ the impact of events scale (IES), ${ }^{30}$ duration of post-traumatic amnesia, and three tests of divided attention were used to assess patients with mild or moderate head injuries at 7-10 days after trauma. Results from all these measures were then correlated with scores from the $R P Q$ readministered three months after injury.

\section{Methods}

PATIENTS

The patients were 50 adults $(23$ men and 27 women) with a mean age of 33 (SD 12.7), range 17-65 years. They had a mean posttraumatic amnesia of seven hours (SD 10.2), ranging from 0 to 44 hours. Two of the patients had post-traumatic amnesia of more than 24 hours (36 and 44 hours). They were included because conventional definitions of severity of injury based on post-traumatic amnesia are known to have a large degree of variability, particularly when cut off points in the definitions occur. The causes of head injury were 20 road traffic accidents, 13 falls, five assaults, five horse riding accidents, and seven other. They were consecutive consenting patients registered with the Oxford Head Injury Service (OXHIS) who had post-traumatic amnesia of less than 48 hours.
MEASURES AND PROCEDURE

Patients were visited in their homes 7-10 days after injury. During this visit a brief structured interview was conducted to ascertain basic epidemiological information including duration of post-traumatic amnesia. Patients also completed an RPQ (a measure of PCS severity), a HADS (a measure of symptoms relating to anxiety and depression), and an IES (a measure of subjective stress in relation to a specific life event; appendix 2). The RPQ presents 16 of the most common published PCS symptoms and asks the patient to rate the degree to which they are any more of a problem compared with premorbid levels using values of $0-4$. A total symptom score can be calculated from the sum of all scores (excluding 1) for which good reliability and adequate validity have been demonstrated. ${ }^{28}{ }^{36}$ Two scores were derived from the HADS; a depression scale score and an anxiety scale score and two scores were derived from the IES; an intrusion scale score (a measure of the extent to which the person experiences intrusive thoughts and feelings about the life event) and an avoidance scale score (a measure of the extent to which the person avoids situations which elicit the aforementioned intrusions). Patients also completed the short orientation memory and concentration test (SOMC) ${ }^{32}$ (appendix 3) as this was already part of the normal OXHIS assessment of patients. This is a short assessment of the person's ability to give basic orientation information and to perform three brief tests of verbal attention and short term memory.

Three tests of divided attention were then administered.

\section{Information processing subtest of the adult} memory and information processing battery $(A M I P B)^{33}$

One hundred and five sets of numbers are presented. Each set consists of five two-figure numbers. The second highest number in each set is cancelled out by the subject as quickly and accurately as possible. The total number of correct responses in four minutes is recorded. A motor speed test is also conducted. This allows an adjusted information processing score to be calculated accounting for the speed taken to cancel out figures. Standardised percentile scores accounting for age are then obtained for $(a)$ the percentage of errors made (error score), (b) the motor speed score (speed score), and (c) the total score adjusted for motor speed (adjusted score).

\section{Stroop test ${ }^{22}$}

A list of 112 words of colours (red, green, blue, and tan) printed in different coloured inks (red, green, blue, and tan) is presented to the subject. In subtask 1 the subject reads the words as quickly and accurately as possible. The number of correct responses in two minutes is recorded. In subtask 2 the subject names the ink colour of each of the words as quickly and accurately as possible and the number of correct responses in two minutes is recorded. A third subtask was also given, 
Table 1 Simple Pearson correlation coefficients ( $r$ ) for all independent measures. Dependent measures: $R P Q$ score at three months after injury and $R P Q$ score at $7-10$ days after injury

\begin{tabular}{|c|c|c|}
\hline \multirow[b]{2}{*}{ Independent measure } & \multicolumn{2}{|c|}{ Dependent measure } \\
\hline & $\begin{array}{l}R P Q \text { Score } \\
\text { at } 3 \text { months } \\
r\end{array}$ & $\begin{array}{l}R P Q \text { Score } \\
\text { at } 7-10 \text { days } \\
r\end{array}$ \\
\hline HADS Anxiety score & $0.57^{\star}$ & $0 \cdot 60^{\star}$ \\
\hline HADS Depression score & $0.54^{\star}$ & $0.65^{\star}$ \\
\hline IES Intrusions score & $0 \cdot 64^{\star}$ & $0 \cdot 69^{\star}$ \\
\hline IES Avoidance score & $0.53^{\star}$ & $0 \cdot 60^{\star}$ \\
\hline SOMC score & $-0 \cdot 38^{\star}$ & -0.26 \\
\hline PASAT $1 \cdot 2$ seconds score & $-0 \cdot 12$ & $-0 \cdot 15$ \\
\hline PASAT1. 6 seconds score & -0.06 & -0.06 \\
\hline PASAT 2.0 seconds score & -0.06 & -0.08 \\
\hline PASAT2.4 seconds score & 0.07 & 0.01 \\
\hline AMIPB Error percentile score & $-0 \cdot 18$ & 0.01 \\
\hline AMIPB Adjusted percentile score & -0.13 & $-0 \cdot 10$ \\
\hline AMIPB Speed percentile score & $-0 \cdot 17$ & -0.29 \\
\hline Stroop 1 score & $0 \cdot 15$ & $0 \cdot 12$ \\
\hline Stroop 2 score & $-0 \cdot 18$ & $-0 \cdot 10$ \\
\hline Stroop 3 score & $-0 \cdot 15$ & -0.05 \\
\hline Post-traumatic amnesia (hours) & 0.12 & -0.01 \\
\hline RPQ (7-10 days) score & $0 \cdot 48^{\star}$ & \\
\hline
\end{tabular}

which was similar to that used by Bohnen et $a l^{25}$ and which has been found to be particularly sensitive to PCS. Twenty two of the colour words were randomly selected and had small rectangles drawn around them. Instructions were the same as for subtask 2 except that the words in rectangles were read rather than the ink colour named. The number of correct responses in two minutes was recorded.

Paced auditory serial addition task (PASAT) ${ }^{21}$

Four series of 61 digits are presented to the subject verbally. Each series is presented at increasingly quicker rates (one digit every $2 \cdot 4$, $2 \cdot 0,1 \cdot 6$, and 1.2 seconds). The subject is

Table 2 Increase in multiple correlation coefficients ( $R$ and $R^{2}$ ) when individual independent measures are added to the regression analysis. Dependent measure $R P Q$ score at three months after injury $(n=45)$

\begin{tabular}{lllr}
\hline Independent measures & $R$ & $R^{2}$ & $(B)$ \\
\hline HADS Anxiety score & 0.55 & 0.30 & $1 \cdot 28^{\star}$ \\
Post-traumatic amnesia (hours) & 0.72 & 0.53 & $0 \cdot 42^{\star}$ \\
SOMC score & 0.76 & 0.58 & $-1 \cdot 79^{\star}$ \\
PASAT2.4 seconds score & 0.78 & 0.61 & $0 \cdot 44^{\star}$ \\
PASAT1.6 seconds score & 0.83 & 0.68 & $-0 \cdot 25$ \\
Stroop 1 score & 0.84 & 0.71 & $0 \cdot 17$ \\
PASAT1.2 seconds score & 0.85 & 0.72 & -0.21 \\
AMIPB Adjusted percentile score & 0.86 & 0.74 & 0.06
\end{tabular}

(B) weights are used to predict values of the dependent measure from the raw scores. (multiple regression equation constant was 23.08 ) $\star \mathrm{P}<0.05$.

Table 3 Increase in multiple correlation coefficients ( $R$ and $R^{2}$ ) when individual independent measures are added to the regression analysis. Dependent measure $R P Q$ score at 7-10 days after injury $(n=50)$

\begin{tabular}{|c|c|c|c|}
\hline Independent measures & $R$ & $R^{2}$ & (B) \\
\hline $\begin{array}{l}\text { IES Intrusions score } \\
\text { SOMC score } \\
\text { Stroop } 1 \text { score } \\
\text { PASAT } 2 \cdot 4 \text { seconds score } \\
\text { PASAT } 2 \cdot 0 \text { seconds score } \\
\text { Stroop } 2 \text { score } \\
\text { PASAT } 1 \cdot 2 \text { seconds score } \\
\text { HADS Depression score } \\
\text { Stroop } 3 \text { score } \\
\text { PASAT } 1 \cdot 6 \text { seconds score } \\
\text { AMIPB Adiusted percentile score }\end{array}$ & $\begin{array}{l}0 \cdot 70 \\
0 \cdot 74 \\
0 \cdot 76 \\
0 \cdot 78 \\
0 \cdot 80 \\
0 \cdot 81 \\
0 \cdot 82 \\
0 \cdot 83 \\
0 \cdot 83 \\
0 \cdot 83 \\
0.84\end{array}$ & $\begin{array}{l}0.50 \\
0.55 \\
0.57 \\
0 \cdot 61 \\
0 \cdot 64 \\
0 \cdot 66 \\
0 \cdot 67 \\
0.68 \\
0 \cdot 69 \\
0.70 \\
0.71\end{array}$ & $\begin{aligned} & 1 \cdot 04^{\star} \\
&-0.84 \\
&-0.46^{\star} \\
&-0.24 \\
& 0.24 \\
&-0.34 \\
&-0.35 \\
& 0.63 \\
& 0.08 \\
& 0.18 \\
& 0.04\end{aligned}$ \\
\hline
\end{tabular}

(B) weights are used to predict values of the dependent measure from the raw scores. (multiple regression equation constant was $86 \cdot 95$ )

$\star \mathrm{P}<0.05$. required to add each digit to the one immediately preceding it and the answer is given aloud. The percentage number of correct responses was recorded for each of the four presentation speeds.

At three months after injury, patients were posted a letter asking them to complete an enclosed RPQ. The completed questionnaire was returned using a stamped addressed envelope (also enclosed). If a patient failed to return the questionnaire within three weeks they were contacted by telephone and an RPQ was administered verbally. At three months after injury five patients were uncontactable having failed to return the RPQ. Data were thus collected on 45 patients; 36 of these completed the RPQ by post and nine verbally. It should be noted that the original validation study of the RPQ included the questionnaires being completed by post. ${ }^{28}$

Stepwise regression analysis was used to evaluate the combined ability of the measures taken 7-10 days after injury to predict the severity of PCS at three months. It was also used to determine the contribution these measures made to the severity of PCS at $7-10$ days. Dependent measures were therefore total RPQ score at three months after injury and total RPQ score at 7-10 days. Regression analysis determines the group of predictor variables that best predict the dependent measure. Simple Pearson correlation coefficients (r) were calculated for all independent measures (predictor variables). All independent measures were then entered into regression analysis using SPSSPC (stepwise regression command). Independent measures remained in the regression analysis only if they increased the explained variance by at least $1 \%$ (as indicated by the value of $R^{2}$ ). The final regression equation gives a parsimonious prediction of the dependent measure.

\section{Results and discussion}

Table 1 shows the simple Pearson correlation coefficients ( $r$ ) for each independent measure when the dependent measures were the total RPQ score at three months after injury and the total RPQ score at 7-10 days after injury.

Table 2 gives the stepwise multiple regression analysis with the total RPQ score at three months after injury as the dependent measure. It shows the increase in the multiple regression coefficient $(R)$ and $R^{2}$ when each independent measure is added to the regression analysis. It also displays the unstandardised regression coefficients (B) for each independent measure in the analysis. These can be used to calculate the regression equation and thus to predict values of the dependent measure from the raw scores of the independent measures.

Table 3 shows stepwise multiple regression analysis with the total RPQ score at 7-10 days as the dependent measure. It shows the increase in $R$ and $R^{2}$ when each independent measure is added to the regression analysis. Unstandardised regression coefficients (B) for each independent measure are also given. 
Table 4 Distribution of RPQ total scores at 7-10 days and three months after injury

\begin{tabular}{lcccccc}
\hline \multicolumn{7}{c}{$R P Q$ Total Scores } \\
\cline { 2 - 7 } & 0 & $1-10$ & $11-20$ & $21-30$ & $31-40$ & $41+$ \\
\hline $7-10$ days $(\mathrm{n}=50)(\mathrm{n}(\%))$ & $3(6)$ & $15(30)$ & $13(26)$ & $10(20)$ & $5(10)$ & $4(8)$ \\
3 months $(\mathrm{n}=45)(\mathrm{n}(\%))$ & $16(36)$ & $16(36)$ & $3(7)$ & $5(11)$ & $4(9)$ & $1(2)$ \\
\hline
\end{tabular}

Table 4 summarises the distribution of total RPQ scores at 7-10 days and three months after injury. It shows that $6 \%$ of the patients were asymptomatic at $7-10$ days and $36 \%$ had scores of 10 or less. At three months improvement in symptoms was such that $36 \%$ were asymptomatic and $72 \%$ had scores of 10 or less.

Table 1 shows that the independent measures which had the strongest relations with the total RPQ score at three months after injury were the scores from the HADS and IES measures. Each of them correlated moderately well with the RPQ scores (at three months). It would therefore seem that the measures of emotional factors rather than the neuropsychological or traditional measures were the best individual predictors of severity of PCS at three months.

Table 2 shows that a combination of emotional, neuropsychological, and traditional measures taken early after injury predicted severity of PCS well at three months. Eight of these measures together accounted for $74 \%$ of the variance in total RPQ scores. This compares with $30 \%$ of the variance accounted for by the HADS anxiety score alone and 3\% of the variance that would be expected to be accounted for by random data alone (using the " $R$ for random data equation" from Howell ${ }^{34}$ ). The predictive ability of the independent measures is therefore significantly enhanced by using a combination of different types of measure together.

Table 1 indicates that all four scores from the HADS and IES had moderately high correlations with the total RPQ score (three months). By contrast, however, table 2 shows that only one of these scores was eventually entered in the stepwise multiple regression analysis. This suggests that a significant degree of collinearity exists between these measures. This is consistent with the finding that it is a combination of different types of measures which maximises the predictive ability of the independent measures.

It should be noted that table 1 shows a very weak correlation between post-traumatic amnesia and total RPQ score at three months. Table 2, however, shows that when post-traumatic amnesia was added to the regression analysis it accounted for an additional $23 \%$ of the variance in RPQ scores. It is therefore possible that post-traumatic amnesia makes a relatively unique contribution to the ability of the independent measures to predict severity of PCS at three months.

Table 1 also shows that the correlation between RPQ score at 7-10 days and three months was significant but not substantial
$(+0.48)$. This might be expected from those theories of PCS development which emphasise both organic and emotional factors. Some consistency in relative severity of PCS over time would be expected with organic factors being a feature of the sequelae but high correlations would not necessarily be expected because of the variation in the emotional impact of the event which caused the head injury and the PCS themselves.

A close examination of table 2 shows that only five scores accounted for $68 \%$ of the variance in RPQ scores (three months). These were the HADS anxiety, post-traumatic amnesia, SOMC, PASAT $2 \cdot 4$, and PASAT $1 \cdot 6$. The other three scores accounted for only an additional $6 \%$ of the variance. From a clinical viewpoint these results might have important implications. For clinicians wishing to identify early after head injury those patients likely to have persistent PCS it is possible that a screening battery of just four measures (HADS, PTA, SOMC, and PASAT) might be of significant help. The $R P Q$ would also be recommended so that a measure of current PCS is included. Patients could then be targeted for ongoing specialist intervention. At the very least such a battery might help clinicians in the difficult task of advising patients with mild and moderate head injuries when they should expect to be able to return to premorbid levels of work and leisure activities. A regression formula specifying the relative weights that should be given to these measures would help clinicians in these tasks. This is not appropriate, however, with the present data as cross validation via an independent sample is required. It is hoped that this will be possible with future research.

For RPQ score at 7-10 days after injury, table 1 shows that the measures which had the strongest individual correlations with RPQ score (7-10 days) were scores from the IES and HADS - that is, measures of emotional factors. It also shows that there was almost a zero correlation coefficient between post-traumatic amnesia and total $R P Q$ score (7-10 days). This suggests that there is no significant relation between posttraumatic amnesia and severity of PCS and lends some support to the findings of Middelboe et al. ${ }^{14}$

It is also interesting to note from table 1 that the total RPQ score at 7-10 days was not significantly correlated with any of the neuropsychological tests of divided attention (Stroop, PASAT, and AMIPB subtests). This superficially seems to be in direct contrast wiith the findings of Bohnen et $\mathrm{l}^{25}$ on the Stroop test and Gronwall's ${ }^{21}$ on the PASAT. Both found positive relations between PCS and tests of divided attention. On close examination, however, Bohnen et al reported that no significant relation existed at 10 days after head injury and that the Stroop test only mirrored PCS change between five weeks and three months after injury. Similarly, Gronwall reports a correlation between PCS and PASAT performance only for subjects 
with post-traumatic amnesia of less than one hour. She found that for her patients with more severe head injury (post-traumatic amnesia of over one hour) PCS and post-traumatic amnesia were not correlated. The mean post-traumatic amnesia for patients in the present study was seven hours which suggests a population more akin to Gronwall's more severely injured sample. The results from this study on closer analysis therefore, tend to confirm previous studies on PCS and tests of divided attention.

The results in table 1 concerning $R P Q$ scores at 7-10 days may have some implications for current models of the causes and development of PCS. Some theorists assert that organic factors play a greater part in PCS early on after injury and emotional ones play a greater role when PCS persist. The results cannot shed any light on the role of organic factors in PCS as no valid measure of organicity in mild head injuries has been identified. The results do, however, show that all significant correlations with severity of PCS came from IES and HADS scores. This suggests that emotional factors play an important part in the early development of PCS. This in no way infers that emotional factors cause PCS as such an inference cannot be made from correlational statistics. It does suggest, however, that emotional factors should possibly be considered as part of the early development of PCS. Such a suggestion is consistent with the finding that emotional factors, including stress, are common mediating factors in the exacerbation of PCS soon after head injury. ${ }^{35}$

Table 3 shows that a combination of 11 of the independent measures predicted PCS severity at 7-10 days moderately well. Together they accounted for $71 \%(R=0.84)$ of the variance in total $R P Q$ scores (7-10 days). Table 3 also shows that the IES intrusion scale score alone accounted for $50 \%$ of the variance. In other words the remaining 10 measures accounted for only an additional $21 \%$ of the variance. This could be interpreted as further support for the assertion that emotional factors may play some part in PCS early after head injury.

The results provide further evidence for the validity of the RPQ as a measure of severity of PCS. Tables 2 and 3 show that the total PCS score at both 7-10 days and three months was best predicted by a combination of emotional, cognitive, and traditional measures. This is precisely what would be predicted from current models of PCS which acknowledge psychological, neuropsychological, and organic factors in the development of such symptoms. In addition, Table 1 indicates a significant correlation between RPQ scores at 7-10 days and three months. This too would be the expected result with the RPQ reliably measuring severity of PCS.

Two limitations should be highlighted for this study. Firstly, the single outcome measure (total RPQ score) relies on postal administra- tion. Secondly, the validity of the total RPQ score as a measure of severity of PCS has yet to be fully demonstrated. Although having some validity, these facts should be set against (a) the high proportion of PCS follow up studies which rely on postally administered outcome measures, ${ }^{101418}$ (b) the validation study of the RPQ which showed good testretest reliability when the measure was administered postally, ${ }^{28}$ and (c) a recent study showing a moderately good correlation $(r=+0.67)$ between the total RPQ score and a recently developed measure designed to assess psychosocial outcome six months after injury. ${ }^{36}$ The latter is a particularly useful measure against which the RPQ has been validated. It assesses common difficulties in everyday functioning which can be affected by PCS and as such may be a unique measure. It therefore goes some way towards establishing the ecological validity of the RPQ. A fuller account of how the RPQ's validity can be assessed can be found in King et al. ${ }^{28}$

It should be noted that the study used a relatively large number of variables $(n=17)$ with a moderate size sample $(n=50)$ and that all generalised conclusions drawn from the regression analysis of a single set of data should be treated with caution. For both these reasons it is necessary that the results are confirmed by cross validation studies on independent samples before conclusions from this study can be considered as ones entirely pertinent to all patients with head injury. The study does, however, provide valuable guidance regarding those measures most likely to be clinically useful.

In conclusion, the results show that measures of emotional factors taken early after injury were the best individual predictors of severity of PCS three months after head injury. These measures, however, seem to have a significant degree of collinearity. When used together with neuropsychological and traditional measures of severity of head injury, their combined ability to predict the severity of PCS at three months is good although cross validation studies are required to confirm this. Together such measures may significantly help a clinician identify early on patients likely to require ongoing specialist intervention. A brief screening battery made up of the HADS, post-traumatic amnesia, PASAT, SOMC, and RPQ is recommended both for its combined predictive power and its clinical utility.

I thank Mrs Joanna McGrath, Clinical Psychology Department, Rivermead Rehabilitation Centre, Oxford, Mr David Quinn, Clinical Psychology Department, Newtown Road Hospital, Worcester, Professor Jim Orford, School of Psychology, Birmingham University, Dr Derick Wade, Rivermead Rehabilitation Centre, Oxford, and Mrs Sue Crawford, Oxford Head Injury Service, Rivermead Rehabilitation Centre, Oxford for their comments and advice on draft versions on this manuscript; Mrs Ann White for her administrative and secretarial contribution; and the Department of Health for funding the Oxford Head Injury Service as part of their traumatic brain injury initiative. 
Appendix 1

RIVERMEAD

REHaBilitation

CENTRE

Abingdon Road, OXFORD, OX1 4XD

Name/Identity

Copyright RRC June 29th 1993 Reproduce freely, but acknowledge source

\section{- Rivermead Post Concussion Symptoms (RCS) Questionnaire}

DATE:

After a head injury or accident some people experience symptoms which can cause worry or nuisance. We would like to know if you now suffer any of the symptoms given below. As many of these symptoms occur normally, we would like you to compare yourself now with before the accident.

For each one please circle the number closest to your answer.

$0=$ Not experienced at all

$1=$ no more of a problem

$\mathbf{2}=$ a mild problem

$3=$ a moderate problem

$4=\mathrm{a}$ severe problem

Compared with before the accident,

do you now (i.e. over the last 24 hours) suffer from:

Headaches

Feelings of dizziness

Nausea and/or vomiting

Noise sensitivity, easily upset by loud noise

Sleep disturbance

Fatigue, tiring more easily

Being irritable, easily angered

Feeling depressed or tearful

Feeling frustrated or impatient

Forgetfulness, poor memory

Poor concentration

Taking longer to think

Blurred vision

Light sensitivity, easily upset by bright light

Double vision

Restlessness

Are you experiencing any other difficulties?

Please specify, and rate as above:

1.

2.

$\begin{array}{lllll}\mathbf{0} & 1 & 2 & 3 & 4 \\ \mathbf{0} & 1 & 2 & 3 & 4 \\ \mathbf{0} & 1 & 2 & 3 & 4 \\ \mathbf{0} & 1 & 2 & 3 & 4 \\ \mathbf{0} & 1 & 2 & 3 & 4 \\ \mathbf{0} & 1 & 2 & 3 & 4 \\ \mathbf{0} & 1 & 2 & 3 & 4 \\ \mathbf{0} & 1 & 2 & 3 & 4 \\ \mathbf{0} & 1 & 2 & 3 & 4 \\ \mathbf{0} & 1 & 2 & 3 & 4 \\ \mathbf{0} & 1 & 2 & 3 & 4 \\ \mathbf{0} & 1 & 2 & 3 & 4 \\ \mathbf{0} & 1 & 2 & 3 & 4 \\ \mathbf{0} & 1 & 2 & 3 & 4 \\ \mathbf{0} & 1 & 2 & 3 & 4 \\ \mathbf{0} & 1 & 2 & 3 & 4\end{array}$

\section{Appendix 2}

\begin{tabular}{|c|c|c|}
\hline Date: & Impact of Event Scale & Case No: \\
\hline
\end{tabular}

Below is a list of comments made by people after stressful life events such as your recent accident. Please check each item, indicating how frequently these items were true for you during the past seven days. If they did not occur at all, please mark the 'not at all' column.

Comment

1 I thought about it when I didn't mean to

2 I avoided letting myself get upset when I thought about it or was reminded of it

3 I tried to remove it from memory

$4 \mathrm{I}$ had trouble falling asleep or staying asleep because of pictures or thoughts about it that came into my mind

5 I had a wave of strong feelings about it

6 I had dreams about it

7 I stayed away from reminders of it

8 I felt as if it hadn't happened or wasn't real

9 I tried not to talk about it

10 Pictures about it popped into my mind

11 Other things kept making me think about it

12 I was aware that I still had a lot of feelings about it but I didn't deal with them

13 I tried not to think about it

14 Any reminder brought back feelings about it

$15 \mathrm{My}$ feelings about it were kind of numb

SCORE: Intrusion Items Avoidance Items \begin{tabular}{lll} 
Not & Rall arely & $\begin{array}{l}\text { Some- } \\
\text { times }\end{array}$ Often \\
\hline
\end{tabular}
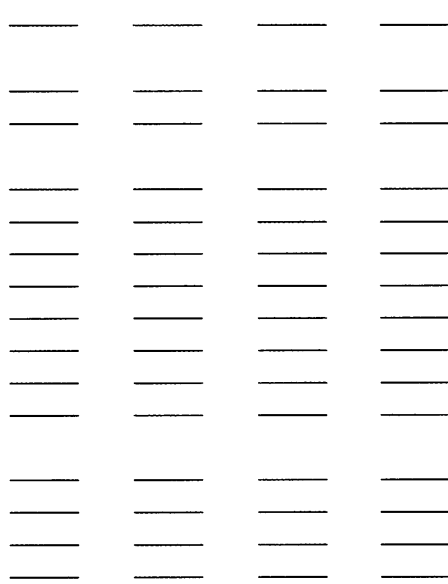
Appendix 3

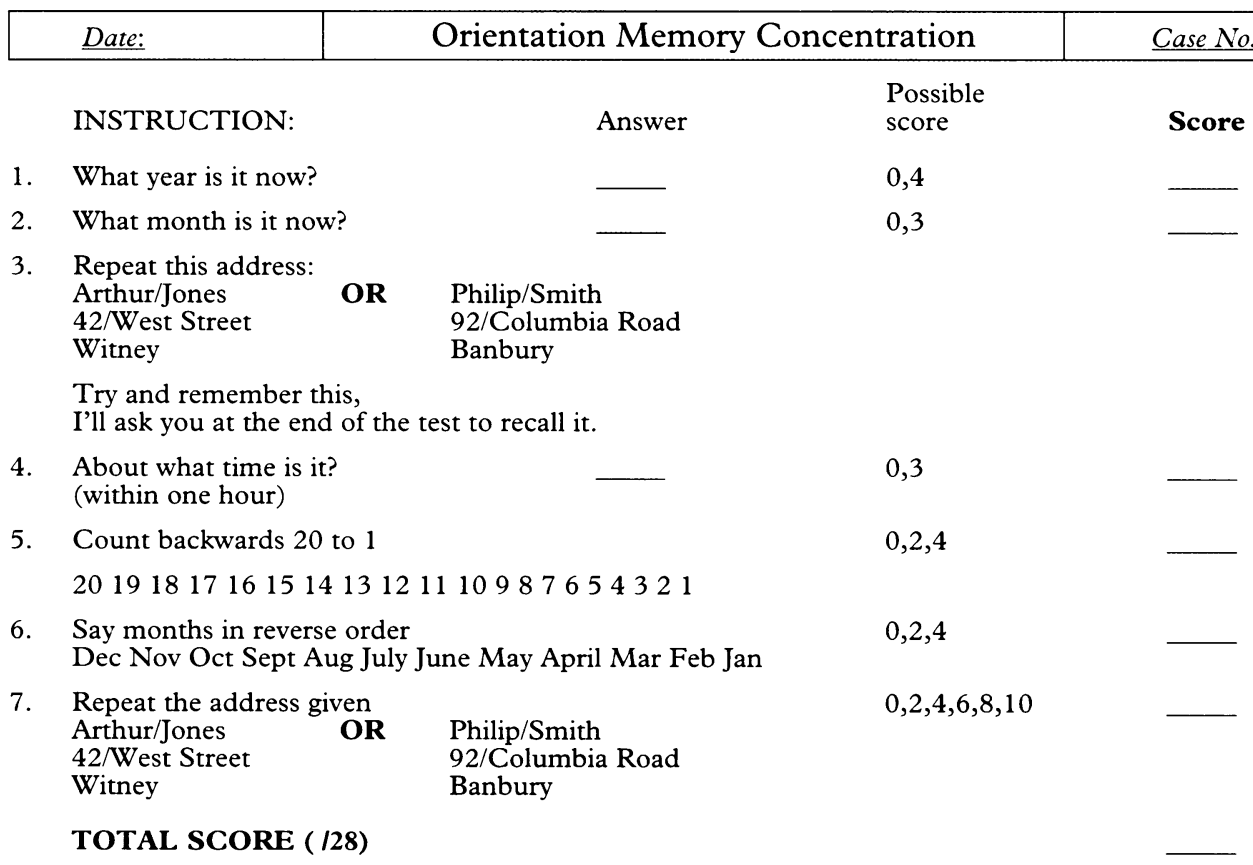

1 Russell WR, Smith A. Post traumatic amnesia after closed head injury. Arch Neurol 1961;5:16-29.

2 Medical Disability Society. The management of traumatic brain injury London: Royal College of Physicians, 1988.

3 Dikmen SS, Temkin N, Armsden A. Neuropsychological recovery; the relationship between psychosocial functioning and post concussional complaints. In: Levin $\mathrm{H}$, ing and post concussional complaints. In: Levin $\mathrm{H}$,
Eisenberg HM, Benton AL, eds. Mild head injury. New Eisenberg HM, Benton AL, eds. Mild head inju
York: Oxford University Press, 1989:229-41.

4 Bohnen N, Twijnstra A, Jolles J. Post-traumatic and emotional symptoms in different sub groups of patients with mild head injury. Brain 1992;6:481-6.

5 Alves WM, Colohan ART, O'Leary TJ, Rimel RW, John JA. Understanding post-traumatic symptoms after mino head injury. Fournal of Head Trauma Rehabilitation 1986 1:1-12.

6 Rutherford WH. Postconcussion symptoms: relationship to acute neurological indices. Individual differences and circumstances of injury. In: Levin $\mathrm{H}$, Eisenberg $\mathrm{HM}$, Benton AL, eds. Mild head injury, New York: Oxford University Press, 1989:217-28.

7 Evans RW. The post concussion syndrome and the sequelae of mild head injury. Neurol Clin 1992;10:815-47.

8 Rimel RW, Giordani B, Barth JT. Disability caused by minor head injury. Neurosurgery 1981;9:221-8.

9 Binder LM. Persisting symptoms after mild head injury. A review of the post concussive syndrome. F Clin Exp Neuropsychol 1986;8:323-46.

10 Rutherford WH, Merrett JD, McDonald JR. Symptoms a one year following concussion from minor head injuries. Injury 1979;10:225-30

11 Englander J, Hall K, Simpson T, Chaffin S. Mild traumatic brain injury in an uninsured population; subjective complaints and return to employment. Brain Inj 1992;6: 161-6.

12 Levin H, Mattis S, Ruff RM. Neurobehavioural outcome following minor head injury; a three centre study. $f$ following minor head injury

13 Caprusso DX, Levin H. Cognitive impairment following head injury. Neurol Clin 1992;10:879-93.

14 Middelboe T, Anderson HS, Birket-Smith M, Friis ML Minor head injury: impact on general health after one year. A prospective follow up study. Acta Neurol Scand

15 Dikmen S, McLean A, Temkin N. Neuropsychological and psychosocial consequences of minor head injury. $\mathcal{F}$ Neurol Neurosurg Psychiatry 1986;49:1227-32.

16 Wrightson $\mathrm{P}$, Gronwall $\mathrm{D}$. Time off work and symptoms after minor head injury. Injury 1981;12:445-54

17 Jakobsen J, Baadsgaard SE, Thomsen S, Henriksen PB. Prediction of post concussional sequelae by reaction time test. Acta Neurol Scand 1987;75:341-5.

18 Minderhoud JM, Boelens MEM, Huizenga J, Saan RJ. Treatment of minor head injuries. Clin Neurol Neurosurg 1980;82:127-40.

19 Ruff RM, Levin H, Mattis S, et al. Recovery of memory after mild head injury: a three center study. In: Levin H,
Eisenberg HM, Benton AL, eds. Mild head injury, New York: Oxford University Press, 1989:176-88.

20 MacFlynn G, Montgomery EA, Fenton GW, Rutherford W. Measurement of reaction time following minor head injury. $\mathcal{F}$ Neurol Neurosurg Psychiatry 1984;47:1326-31.

21 Gronwall D. Performance changes during recovery from closed head injury. Proceedings from the Australian Association of Neurologists 1976;13:143-7.

22 Trenerry MR, Crosson B, DeBoe J, Leber WR. Stroop neu ropsychological screening manual. Florida: Psychological Assessment Resources Inc, 1989.

23 Gronwall D, Wrightson P. Delayed recovery in intellectua function after mild head injury. Lancet 1974;ii:605-9.

24 Gronwall D. Paced auditory serial addition task: a measure of recovery from concussion. Percept Mot Skills 1977; 44:367-73.

25 Bohnen N, Twijnstra A, Jolles J. Performance in the Stroop colour test in relationship to the persistence of symptoms following minor head injury. Acta Neurol Scand 1992; 85:116-21.

26 Rutherford WH, Merrett JD, McDonald JR. Sequelae of concussion caused by minor head injuries. Lancot 1977 i: $1-4$.

27 Bohnen N, Twijnstra A, Jolles J. Neuropsychological deficits in patients with persistent symptoms six month after mild head injury. Neurosurgery 1992;30:692-6.

28 King NS, Crawford S, Wenden FJ, Moss NEG, Wade DT. The Rivermead post concussion symptoms questionnaire-a measure of symptoms commonly experienced after head injury and its reliability. 7 Neurol 1995;242. 587-92.

29 Zigmond AS, Snaith RP. The hospital anxiety and depression scale. Acta Psychiatr Scand 1983;67:361-70.

30 Horowitz MJ, Wilner N, Alvarez W. Impact of event scale: measure of subjective stress. Psychosom Med 1979;41: 209-18

31 Bishara SN, Partridge FM, Godfrey RG, Knight FG. Post traumatic amnesia and Glasgow coma scale related to outcome in survivors in a consecutive series of patients with severe closed head injury. Brain Inj 1992:6:373-80.

32 Katzman R, Brown T, Fuld P, Peck A, Schechter R, Schimmel $\mathrm{H}$. Validation of a short orientation-memory concentration test of cognitive impairment. $\mathrm{Am} \mathcal{F}$ Psychiatry 1983;140:737-9.

33 Coughlan A, Hollows SE. Adult memory and information processing battery. St James' University Hospital, Leeds: Psychology Department Publication, 1985.

34 Howell DC. Multiple regression. In: Statistical methods for psychology. Belmont: Duxbury Press, 1992:484-524.

35 Moss NE, Crawford S, Wade DT. Post concussion symptoms: is stress a mediating factor? Clinical rehabilitation 1994;8:149-56.

36 Crawford S, Wenden F, Wade DT. The Rivermead head injury follow-up questionnaire. A study of a new rating scale and other measures to evaluate outcomes after head injury. F Neurol Neurosurg Psychiatry 1996;60:510-14. 